\title{
EFFECT OF SPRINKLER IRRIGATION ON GROWTH OF PAULOWNIA SHAN TONG TREES AT FIRST TWO YEARS OF CULTIVATION IN LIGHT SOIL
}

\author{
Ariel Langowski ${ }^{1}$, Roman Rolbiecki ${ }^{1}$, Stanislaw Rolbiecki ${ }^{1}$, Wieslaw Ptach $^{2}$, Paulina Wrobel ${ }^{1}$ \\ ${ }^{1}$ UTP University of Science and Technology in Bydgoszcz, Poland; \\ ${ }^{2}$ Warsaw University of Life Sciences, Poland \\ ariel.langowski@utp.edu.pl,rolbs@utp.edu.pl,wieslaw_ptach@sggw.pl,pauwro000@utp.edu.pl
}

\begin{abstract}
The effect of sprinkler irrigation on the growth of Paulownia Shan Tong trees was investigated. The field experiment was carried out during the years 2016-2017 on sandy soil in the forest nursery Białe-Błota (Bydgoszcz Forest Division, Poland). The experiment was established as one factorial. The variability factor was irrigation: S- sprinkler irrigation and C- without irrigation (control). The irrigation scheduling was done according to tensiometer indications. Irrigation was started, when the water potential in the soil was $-40 \mathrm{kPa}$. Sprinkler irrigation was done using the NAAN sector sprinklers. Water for irrigation was taken from a deep well. The process included the controls of growth parameters: tree height, trunk diameter, number of leaves. It was found that the sprinkled seedlings of Paulownia Shan Tong were significantly higher than those growing in the non-irrigated plots. The sprinkler irrigation applied in the experiment resulted in an increase in the number of leaves of Paulownia. By analysing the results of the study on the trunk diameter, leaf number, it may be stated that irrigation watering significantly influenced the tested parameters. Irrigation significantly increased the height of Paulownia trees. The positive effect of the usage of sprinkler irrigation may indicate the possibility of effective application of this method in field cultivation of Paulownia Shan Tong.
\end{abstract}

Keywords: Paulownia, Shan Tong, growth, forest nursery, sprinkler irrigation.

\section{Introduction}

Paulownia species are indigenous to China and have been used as agroforestry trees for over 2600 years due to their many positive attributes and multifaceted uses. The genus was named in honour of Queen Anna Pavlovna from The Netherlands (1795-1865), the daughter of Tsar Paul I of Russia [1]. It is also called the Chinese Empress tree, the Princess tree or the Kiri tree. Zhao-Hua et al. [2] state that there are nine major species in the Paulownia genus, which are all native to East Asia. Paulownia, in particular P. tomentosa, has been planted as an ornamental tree in NW Europe since the early 1800's, but has not been considered as a possible commercial species in the region until the last few years. The results of the studies, based on the data gathered from the existing sites, presented by Jensen [3], indicate that Paulownia species and the hybrids could grow successfully as a commercial agroforestry crop in north-western Europe. Paulownia can be propagated by seeds, roots or stem cuttings. There are many commercial hybrids, available for sale from plant nurseries, depending on the climate and commonly available in Europe. Wenhua [4] noted that some excellent Paulownia hybrids have been bred in recent years, for example, Paulownia fortunei x, Paulownia tomentosa that provide up to $30 \%$ higher timber volume than Paulownia elongate, while still being suitable for intercropping.

Paulownia trees are characterized by a wide range of uses. The goals of Paulownia planting are site reclamation, animal waste utilization, rapid biomass production, or pulpwood for paper production [5]. Paulownia is an appropriate tree for intensive management in hardwood plantations with short rotation because of its rapid growth, ability to stump sprout and the wide variety uses for its wood and fiber. Paulownia does not require replanting after harvest, because it regenerates from stump sprouts. Paulownia wood is used for a multitude of products, because it is attractive, strong, lightweight, quickdrying, versatile and has good resonance qualities. The wood is easily worked and will not split or crack when spikes are driven into it or with rapid drying [6]. Due to the high price of balsa, Paulownia wood is also used as an element of composite construction material, which can replace balsa wood in sandwich structures applied among ships, aircrafts, automobiles or wind energy systems [7]. It has been recorded that an 8-10 year old Paulownia tree can produce $100 \mathrm{~kg}$ of fresh leaves per year [8]. The leaves and flowers of Paulownia are rich in nitrogen and other nutrients, which could serve as good natural fertilisers [8]. Furthermore, the leaves of Paulownia have high nutritive content suitable for ruminants [9] and can be ensiled as a fodder crop. The leaves are also fed to pigs and rabbits $[2 ; 8]$.

The plant analyzed in this paper is a hybrid of Paulownia called Shan Tong, characterized by very rapid growth (trunk diameter, after 8-10 years, reaches $50 \mathrm{~cm}$ ), resistance to low temperatures (to $-27^{\circ} \mathrm{C}$ ), strong root system and large leaves (up to $60 \mathrm{~cm}$ wide), light and easy to processing wood 
(40\% lighter than pine) [10]. In Poland, Paulownia Shan Tong is a new species, introduced due to the potential benefits of growing for paper, furniture and biomass production. There is a very rare number of publications about Paulownia in Poland. The experiments on the influence of chosen saccharides on the growth and development of the in vitro shoot cultures of Paulownia tomentosa were made by Litwińczuk and Bochnia [11]. The researches to examine the usefulness of Paulownia tomentosa for cultivation for biomass in south-eastern Poland were made by Jacek and Litwińczuk [12]. The results of their researches show that Paulownia plantations can be recommended in sandy soils under the condition of provision of an irrigation system. Sprinkler irrigations systematically deliver optimal doses of water to plants and are characterized by a high water utilization rate [13]. The effect of using this type of irrigation is to provide conditions for production of valuable seedlings [14].

The main aim of the study was to determine the influence of sprinkler irrigation on the growth parameters of Paulownia Shang Tong in the first two years of growing on light soil in a low rainfall area.

\section{Materials and methods}

The experiments were carried out during 2016 and 2017 vegetation seasons at the forest nursery "Białe Błota" (Bydgoszcz Forest Division, Poland). Experiments were run on a brown podzolic soil formed from a loose sandy soil. Two years old seedlings (from rootstock) were planted in two rows with spacing of 5 meters in a row and 3 meters between the rows. The experiment was designed as one-factorial trial. The main factor was: irrigation, used in two variants (sprinkler irrigation and control - without irrigation). During the experiment the following features were determined: height, diameter of the trunk and the number of leaves. The obtained data, according to the design of the experiment, were tested by one-factorial analysis of variance with the Tukey test (Statistica ANOVA).

Meteorological conditions. The average air temperature during the 2016 vegetation season was $14.9^{\circ} \mathrm{C}$ and for 2017 vegetation season $14.3^{\circ} \mathrm{C}$ (Table 1). As compared to the multiyear average (1981-2010), 2016 was characterized by the highest average temperature $\left(+0.4^{\circ} \mathrm{C}\right)$. But the average temperature of 2017 was slightly lower. Temperatures higher than mean values for 1981-2010 were observed in April, May, June and September of 2016. 2017 was characterized in mostly months with the temperatures lower than multiyear average. Total rainfall measured during the vegetation season of 2016 was $358 \mathrm{~mm}$ and was higher than the average value from many years by $27.6 \%(77.5 \mathrm{~mm})$ (Table 2).

Table 1

Air temperature in the vegetation periods 2016 and 2017 in the vicinity of Bydgoszcz

\begin{tabular}{|c|c|c|c|c|c|c|c|}
\hline \multirow{2}{*}{ Years } & \multicolumn{7}{|c|}{ Air temperature, ${ }^{\circ} \mathrm{C}$} \\
\cline { 2 - 8 } & IV & V & VI & VII & VIII & IX & IV-IX \\
\hline 2016 & 8.3 & 14.7 & 17.7 & 18.3 & 16.4 & 14.3 & 14.9 \\
\hline 2017 & 6.8 & 13.4 & 16.8 & 17.7 & 17.7 & 13.1 & 14.3 \\
\hline $1981-2010$ & 7.9 & 13.3 & 16.1 & 18.6 & 17.9 & 13.1 & 14.5 \\
\hline Average 2016-2017 & 7.6 & 14.0 & 17.2 & 18.0 & 17.0 & 13.7 & 14.6 \\
\hline Deviation from long-term average, \% & -3.8 & +5.3 & +6.8 & -3.2 & -5.0 & +4.6 & +0.8 \\
\hline
\end{tabular}

Rainfall in the vegetation periods 2016 and 2017 in the vicinity of Bydgoszcz

Table 2

\begin{tabular}{|c|c|c|c|c|c|c|c|}
\hline \multirow{2}{*}{ Years } & \multicolumn{7}{|c|}{ Rainfall, mm } \\
\cline { 2 - 8 } & IV & V & VI & VII & VIII & IX & IV-IX \\
\hline 2016 & 28.7 & 51.4 & 98.1 & 133.8 & 55.3 & 19.4 & 386.7 \\
\hline 2017 & 40.8 & 56.3 & 54.3 & 118.9 & 126.1 & 78.4 & 474.8 \\
\hline $1981-2010$ & 27.0 & 49.3 & 52.8 & 69.8 & 62.6 & 46.0 & 307.5 \\
\hline $\begin{array}{c}\text { Average 2016-2017 } \\
\begin{array}{c}\text { Deviation from long-term } \\
\text { average, \% }\end{array}\end{array}$ & 34.7 & 53.8 & 76.2 & 126.3 & 90.7 & 48.9 & 71.8 \\
\hline
\end{tabular}


In the case of 2017, the rainfall was very high and was equal nearly $475 \mathrm{~mm}(167 \mathrm{~mm}$ more than the multiyear sum). In the months from May to July, there was higher rainfall than the average for many years (1981-2010) during the season in 2016. Particularly high rainfall was recorded in July, in which the precipitation amounted to $133.8 \mathrm{~mm}$ (91.7\% more than in many years). In August and September there was a decrease in precipitation. Particularly precipitation in September was $57.8 \%$ lower than the long-term average. In 2017 the amount rainfall of each month was higher than the multiyear average. The highest amount was measured in July, August and September.

Irrigation. Irrigation was done using a solid-set hand-line irrigation system with overhead impact sprinklers mounted on risers. The irrigation radius of the sprinklers was $R=10 \mathrm{~m}$. The water output was $2.5 \mathrm{~m}^{3} \cdot \mathrm{h}^{-1}$. Water for irrigation was taken from the retention reservoir located in the forest nursery. Natural precipitation was measured using a Hellmann rain gauge and was $358 \mathrm{~mm}$ in this period. Sprinkling irrigation was started 14 days after tree seedlings planting (1 May) and ended on 30 September at the 2016 vegetation season. In 2017 the irrigation was started in May. During the first 14 days after planting, the seedlings did not form leaves. Irrigation was used to supplement natural rainfall. Sprinkler irrigation was realized in accordance with the recommendations for forest nurseries on open areas. Terms of irrigation and irrigation doses were established according to tensiometer indications. Irrigation was started, when the water potential in the soil was $-40 \mathrm{kPa}$. The first irrigation was performed 14 days after seedlings planting in 2016. The total irrigation doses applied from 1 May to 30 September were 170 and $120 \mathrm{~mm}$ for 2016 and 2017, respectively (Fig. 1).

The height of Paulownia trees, trunk diameter (measured at the height of $5 \mathrm{~cm}$ ) and the number of leaves for two variants of the experiment were determined.

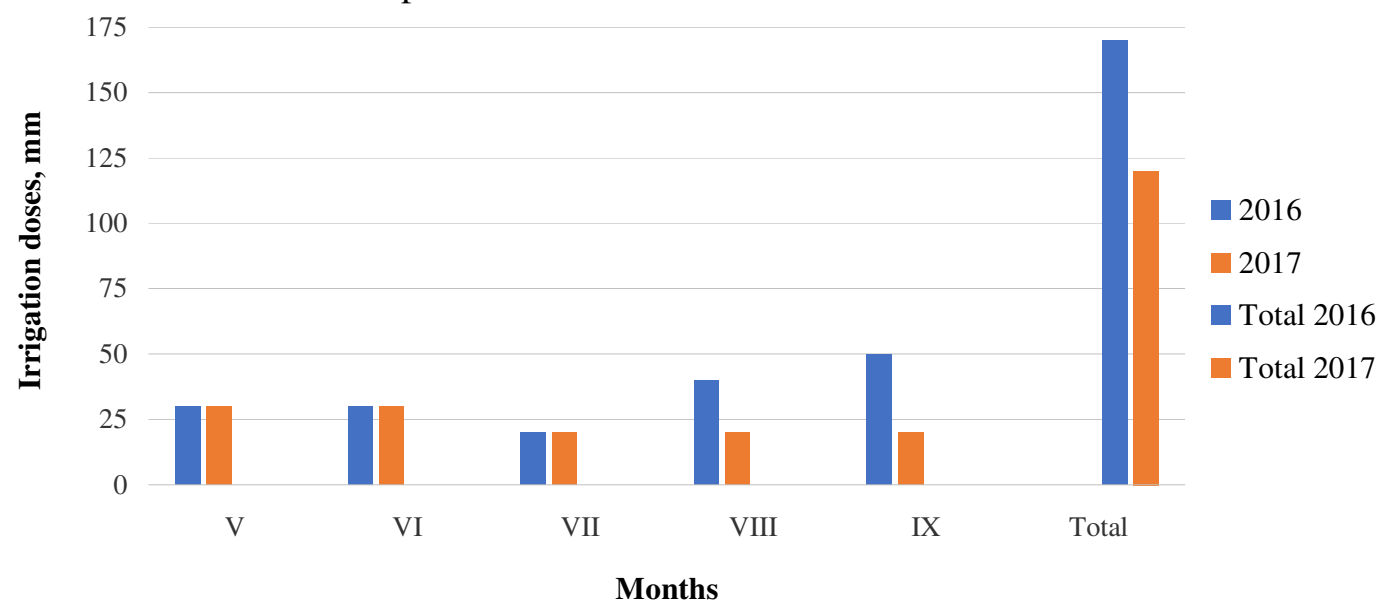

Fig. 1. Irrigation doses during in vegetation period 2016 and 2017

\section{Results and discussion}

Sprinkler irrigation significantly affected the height of Shan Tong Paulownia (Fig. 2). The difference in plant height was observed throughout all months of the vegetation season. The biggest difference between the plant height in the variants of the experiment was observed in the second year of the study (2017). It was equal to nearly $100 \mathrm{~cm}$. In the first year of cultivation the difference between the control and irrigated plants was lower and equal to $53 \mathrm{~cm}$. During the two vegetation seasons (2016 and 2017), the irrigated Paulownia gave an average of $72 \%$ more growth than the nonirrigated trees. The positive similar tendencies and effects of irrigation on the development of different trees in the region of Bydgoszcz were already observed in the case of species, such as Scots pine [15], white birch [16], European larch [17] and little leaf linden [18].

Analyzing the results of the study of the trunk diameter, leaf number and surface during the first two vegetation seasons (2016 and 2017), it can be stated that sprinkler irrigation had a significant influence on the tested parameters. The average increase of the trunk diameter for the control variant was equal to $26 \mathrm{~mm}$, while for the irrigated Paulownia $40 \mathrm{~mm}$ at the first year of cultivation. But significantly higher increases were noted in the second year of the study $2017,30 \mathrm{~mm}$ and $52 \mathrm{~mm}$ at the control and irrigated variants, respectively (Fig. 3). Analyzing the influence of sprinkling irrigation on the increase of the leaf numbers, two stages of growth can be observed (Fig. 4). During the first 
year (2016), the numbers of leaves in both analyzed variants were higher in both variants than in the second year of the experiment (2017).

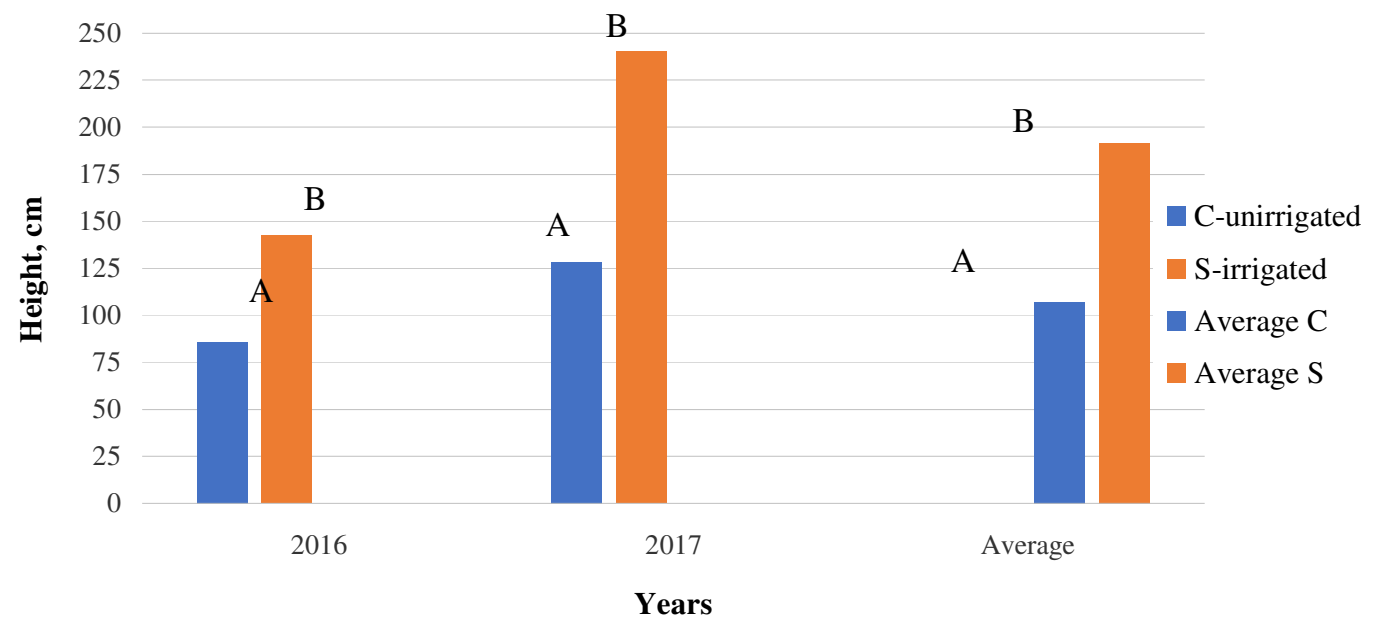

Fig. 2. Height of seedlings for irrigated and unirrigated Paulownia trees observed during 2016 and 2017 vegetation seasons: $\mathrm{A}, \mathrm{B}-$ different letters mean significant differences at $p<0.05$

The results of the experiment are similar to the results presented by Mirkala J.E. and Rad S.R. [19], who have studied the influence of irrigation on Paulownia growth. They noted that more than $80 \%$ of growth took place in the first 3 months of growing.

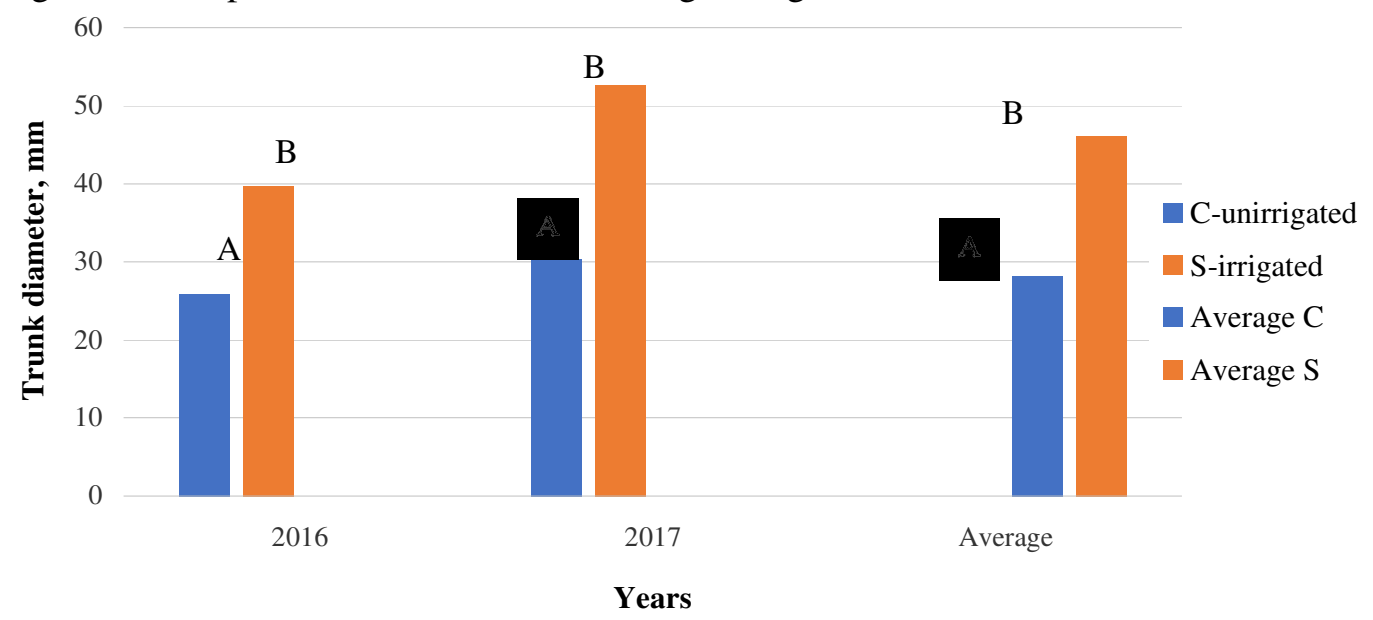

Fig. 3. Trunk diameter for irrigated and unirrigated Paulownia trees observed during 2016 and 2017 vegetation seasons. A, B - different letters mean significant differences at $p<0.05$

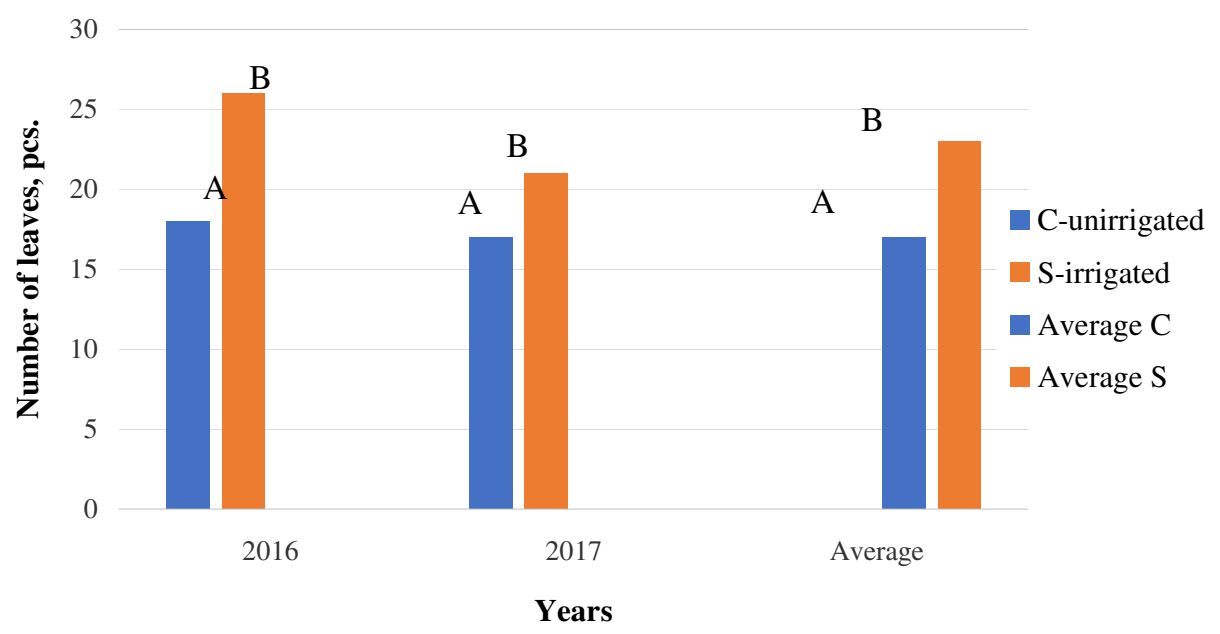

Fig. 4. Number of leaves for unirrigated and irrigated Paulownia trees observed during 2016 and 2017 vegetation seasons: $\mathrm{A}, \mathrm{B}-$ different letters mean significant differences at $p<0.05$ 


\section{Conclusions}

1. The highest significant increases thanks to irrigation of the height and trunk diameter were determined in the second year of the study (2017) and equal to nearly $100 \mathrm{~cm}$ and $22 \mathrm{~mm}$ for the height and trunk diameter, respectively.

2. Sprinkling irrigation significantly increases the leaf numbers in both years of the study, but the highest leaf numbers were obtained during the first vegetation season (2016).

3. The experiment has shown the usefulness of the irrigation technology in Paulownia trees cultivation in the Polish climatic conditions in very light soil.

\section{Acknowledgements}

Acknowledgements are due to the Białe-Błota Forest Nursery Staff for providing the necessary support during the field researches and data collection.

\section{References}

[1] Woods V.B. Paulownia as a novel biomass crop for Northern Ireland? A review of current knowledge. Occasional Publication No 7. Agri-Food and Biosciences Institute. Hillsborough. Northern Ireland, 2008, pp. 56.

[2] Zhao-Hua Z., Ching-Ju C., Xin-Yu L., Yao Gao X. Paulownia in China: Cultivation and Utilisation. Asian Network for Biological Sciences and International Development Research Centre, 1986, [online][30.03.2019] Available at: https://paulowniamp.files.wordpress.com/2010/05/paulownia-in-china.pdf.

[3] Jensen J.B. An investigation into the suitability of Paulownia as an agroforestry species for UK \& NW European farming systems. Department of Agriculture \& Business Management. Scotland`s Rural College. Manuscript, 2016, pp. 206.

[4] Wenhua L. Agro-ecological Farming Systems in China. Man and the Biosphere Series, The Parthenon Publishing, Group Limited, Casterton Hall, 2001, Vol. 26.

[5] Olson J., Carpenter H. Specific gravity, fiber length and extractive content of young Paulownia. Wood and Fiber Science, Vol. 17 (4), 2008, pp. 428-438.

[6] Clatterbuck W.K., Hodges D.G. Tree Crops for Marginal Farmland - Paulownia. PB1465. The University of Tennessee Agricultural Extension Service. Mansuscript, 2004, pp. 33.

[7] Li W., Weiqing L., Hai F., Ding Z. Interlaminar Behavior of Paulownia Wood Sandwich Composites with Grooves. Proceedings of the 5th International Conference on FRP Composites in Civil Engineering. September 27-29, Beijing, China, 2010, p. 123-126.

[8] Wang Q., Shogren J.F. Characteristics of the crop-paulownia system in China. Agriculture, Ecosystems and Environment, Vol. 39, 1992, pp. 45-152.

[9] Bodnár A., Pajor F., Steier J., Kispál T., Póti P. Nutritive value of paulownia (Paulownia spp.) hybrid tree leaves. Hungarian Agricultural Research, Vol. 23, No. 4, 2014, pp. 27-32.

[10] Biomas Energy Project. [online][30.03.2019] Available at: http://www.bep-sa.pl/aktualnosci/ paulownia-zielona-sila-biznesu.html

[11]Litwińczuk W., Bochnia E. Development of Royal Paulownia (Paulownia Tomentosa steud.) in vitro shoot cultures under the influence of different saccharides. Acta Scientiarum Polonorum., Hortorum Cultus, Vol. 11, 2012, pp. 3-13.

[12] Jacek B., Litwińczuk W. The selected biomass properties of Paulownia tomentosa strains cultivated for energy purposes in the first two years of vegetation. Annals of Warsaw University of Life Sciences - SGGW Agriculture No 68 (Agricultural and Forest Engineering), 2016, pp. 61-66.

[13] Kaczmarczyk S., Nowak L. Plants irrigation, State agricultural and forestry publishing house, Poznań, 2006, (In Polish).

[14] Sobczak R. Forest and ornamental forest nurseries. World Publishing House, Warsaw, 1999, (In Polish. 
[15] Klimek A., Rolbiecki S., Rolbiecki R., Hilszczańska D., Malczyk P. Impact of chosen bare root nursery practices in Scots pine seedling quality and soil mites (Acari). Polish Journal of Environmental Studies, Vol. 17, Iss. 2, 2008, pp. 247-255.

[16] Klimek A., Rolbiecki S., Rolbiecki R., Malczyk P. Impact of chosen bare root nursery practices on white birch seedling quality and soil mites (Acari). Polish Journal of Environmental Studies, Vol. 18, Iss. 6, 2009, pp. 1013-1020.

[17] Klimek A., Rolbiecki S., Rolbiecki R., Hilszczańska D., Malczyk P. Effects of organic fertilization and mulching under micro-sprinkler irrigation on growth and mycorrhizal colonization of European larch seedlings, and occurrence of soil mites. Polish Journal of Environmental Studies, Vol. 5, Iss. 20, 2011, pp. 1211-1219.

[18] Klimek A., Rolbiecki S., Rolbiecki R., Długosz J., Musiał M. The use of compost from sewage sludge and forest ectohumus for enrichment of soils in the nursery cultivation of littleleaf linden (Tilia cordata Mill.). Annual Set the Environment Protection, Vol. 15, 2013, pp. 2811-2828.

[19]Rad J.E., Mirkala S.R. Irrigation effects on diameter growth of 2-year old Paulownia tomentosa samplings. Journal of Forests Researches, Vol. 26 (1), 2015, pp. 153-157. 